\title{
Australia's dietary guidelines and the environmental impact of food "from paddock to plate"
}

\section{Our guidelines need to do more for the health of the planet as well as the population}

draft revision of Australia's dietary guidelines was released by the National Health and Medical Research Council (NHMRC) for public comment in December 2011. ${ }^{1}$ Although comprehensive with respect to nutrition, there is minimal reference in the guidelines to the environmental impact of the food supply and what food choices consumers can make to minimise this impact. Continuing to consume food that has a large ecological footprint will threaten our future food supply. As ensuring food security and minimising the environmental impact of food are intrinsically linked, it is time that all involved in making recommendations about food consumption start taking this food and environmental interconnection into account. Recently, the NHMRC released a draft appendix to the revised dietary guidelines, Australian dietary guidelines through an environmental lens. ${ }^{2}$ Although this draft appendix acknowledges the critical need to consider the environmental impact of food "from paddock to plate", the recommendations made are limited, fairly generic and need to be strengthened.

The idea of considering the environmental impact of food in dietary guidelines is not new. The Australian dietary guidelines for adults released in 2003 include an appendix on the sustainability of food systems, which flagged that future dietary guidelines would probably have a greater emphasis on sustainability as "the problems caused by non-sustainable systems become more starkly obvious". ${ }^{3}$ More recently, the Health Council of the Netherlands developed dietary guidelines from an ecological perspective. ${ }^{4}$ Even acknowledging the limitations and complexity of the environmental data about minimising the ecological impact of food production in Australia, there is sufficient information to make stronger statements in the dietary guidelines about some key areas: in relation to fish, bottled water and red meat, the evidence is clear.

Fish stocks globally are collapsing at an alarming rate, with more than three-quarters overexploited or overfished. ${ }^{5}$ Forty per cent of Australia's managed fish stocks have been deemed overfished, ${ }^{6}$ and $72 \%$ of fish now consumed in Australia is imported. ${ }^{7}$ The growth of imports of fish into Australia is mirrored by other developed countries such as the member states of the European Union, which sources around $40 \%$ of its fish from a range of fisheries outside its own exclusive economic zone. ${ }^{5}$ Aquaculture has expanded to meet fish market requirements, but largely relies on fishmeal (usually sourced from small fish caught as bycatch when fishing for target species) as a food source for the fish being farmed.
Linda A Selvey MB BS(Hons), PhD, FAFPHM, Deputy Head

Marion G Carey MB BS(Hons). MPH, FAFPHM, VicHealth Senior Research Fellow ${ }^{2}$

1 School of Public Health, Curtin University, Perth, WA.

2 Monash Sustainability Institute, Monash University, Melbourne, VIC.

linda.selvey@ curtin.edu.au

doi: 10.5694/mjal2.10528

din resource be consumption of a depling resource be considered advisable, given that even current fish consumption levels are exceeding a renewable supply? As was recommended in the Netherlands, ${ }^{4}$ the recommendations in the Australian guidelines should be modified to match population consumption levels that are achievable within catch limits from Australia's exclusive economic zone, and should suggest alternative sources of omega-3 fatty acids (even though the evidence supporting their effectiveness is not as compelling).

The draft dietary guidelines recommend drinking water in preference to other beverages, but make no reference to the impact of consuming bottled water, beyond reference to fluoride and cost. ${ }^{1}$ The draft appendix recommends drinking tap water in preference to bottled water, to decrease the production and disposal of plastic bottles, but does not mention energy consumption. ${ }^{2}$ In Switzerland, a life-cycle analysis (tracing energy use from water catchment and extraction through to drinking) showed that tap water requires less than $1 \%$ of the energy required to produce bottled water. ${ }^{9}$ Bottled water also creates waste and is expensive. The Australian guidelines should recommend against not only bottled water but also other bottled drinks, to minimise environmental impact as well as, in the case of sweetened and carbonated drinks, on health grounds.

Australian men consume $20 \%$ more red meat than the maximum recommended in the draft dietary guidelines, but women, children and infants consume less. ${ }^{1}$ Livestock contributes a significant proportion of agriculture's greenhouse gas (GHG) emissions. ${ }^{10}$ Reducing red meat consumption would not only reduce emissions but would also reduce the risk of colorectal cancer ${ }^{1}$ and the consumption of saturated fat, with associated health Online first 17/12/12 benefits. ${ }^{10}$ Although the draft appendix refers to protein 
sources that have lower environmental impact, ${ }^{2}$ there is no specific mention of the high environmental impact of red meat, particularly beef. In the interest of limiting GHG emissions, the guidelines should strengthen recommendations for men to reduce consumption of red meat, and state more explicitly the environmental benefits of reducing red meat consumption. Other sources of protein, iron and other nutrients could be emphasised.

Several other broad recommendations could also be made more explicitly in the guidelines - for example, to minimise the intake of processed food, to eat fruit and vegetables in season (which is also a much cheaper option), to reduce food waste and to move, in general, to a less meat-based and more plant-based diet.

Also contributing to food security and the environmental impact of food are food production practices and climate. Unsustainable food production practices contribute to land degradation, which is a problem in Australia and globally. It has been estimated that 5.7 million hectares of land in Australia are in regions at risk of or affected by salinity, with this area increasing over time. Soil acidification and erosion are also on the increase in Australia. ${ }^{8}$ To protect Australia's future food supply, Australian farming practices need to be adjusted to minimise further land degradation.

Agriculture produces $16 \%$ of Australia's total GHG emissions, not including emissions attributable to diesel fuel use on farms, food transport and manufacturing. ${ }^{8}$ Changes in climate caused by increases in GHG levels will have significant impacts on food security in Australia and elsewhere. Queensland's wheat industry lost \$150 million in 2009 when a heatwave in winter destroyed the wheat crop in the state's south-east. ${ }^{11}$ Although individual heat events are not directly attributable to climate change, climate modelling predicts increases in heatwaves and changes in rainfall patterns as a result of global warming. In Australia over the past decade, the frequency of record hot days was more than double the frequency of record cold days. $^{12}$

The impact of climate change on agriculture and food production will be a mix of positive and negative effects: while an increase in atmospheric $\mathrm{CO}_{2}$ levels stimulates plant growth, it also results in lower nutrient content of grains. ${ }^{8}$ Overall, the impact of climate change in Australia is considered to be negative, with an estimated $15 \%-30 \%$ decline in food production over the next 40 years. ${ }^{8}$ Clearly, it would be in our interest to minimise the GHG emissions associated with food production, while maintaining adequate nutritional intake.

Although there are ethical challenges to consider when making recommendations in health guidelines beyond the health of the individual, the strong interconnectedness between public health, the environment, food production, and food security should make this inclusion an imperative in the case of dietary guidelines. ${ }^{8}$ The dietary guideline recommendations, themselves, should take every opportunity to incorporate the principles of minimising the environmental impact of the food supply, rather than relegating these to an appendix (implying lesser consideration).

Australia needs to fully recognise the critical importance of minimising the environmental impact of the food supply, and we need more research about the ecological footprint of our food production. In the meantime, Australia's dietary guidelines will form the basis of recommendations that people will be encouraged to follow, as well as providing a benchmark for assessing current consumption. Australians are aware of the importance of good nutrition to health but, as yet, have a can any

recommendation

to increase

consumption

of a depleting

resource be

considered

advisable, given

that even current

fish consumption

levels are

exceeding a

renewable

supply? very low level of awareness about the connection between food and environmental impact. ${ }^{13}$ Awareness has to start somewhere, and Australia's dietary guidelines would be a good place to start.

Competing interests: We are both on the management committee of Doctors for the Environment Australia and are members of the Australian Conservation Foundation. Linda Selvey was formerly the Chief Executive Officer of Greenpeace Australia Pacific.

Provenance: Not commissioned; externally peer reviewed.

1 National Health and Medical Research Council. Australian dietary guidelines incorporating the Australian guide to healthy eating: providing the scientific evidence for healthier Australian diets. Draft for public consultation. Canberra: NHMRC, 2011. http://consultations.nhmrc.gov.au/files/consultations/ n55draftaustraliandietaryguidelinesconsultation111212.pdf (accessed Mar 2012)

2 National Health and Medical Research Council. Public consultation draft on an Appendix to the Australian dietary guidelines. Australian dietary guidelines through an environmental lens. Canberra: NHMRC, 2012. http:// consultations.nhmrc.gov.au/public_consultations/dietary-appendix (accessed Oct 2012).

3 National Health and Medical Research Council. Dietary guidelines for Australian adults. Canberra: NHMRC, 2003. http://www.nhmrc.gov.au/_files_ nhmrc/publications/attachments/n33.pdf (accessed Jul 2012).

4 Health Council of the Netherlands. Guidelines for a healthy diet: the ecological perspective. The Hague: Health Council of the Netherlands, 2011. (Publication no. 2011/08E.) http://www.gezondheidsraad.nl/sites/default/files/ 201108E.pdf (accessed Mar 2012).

5 Brunner EJ, Jones PJS, Friel S, Bartley M. Fish, human health and marine ecosystem health: policies in collision. Int J Epidemiol 2009; 38: 93-100.

6 Srinivasan UT, Watson R, Sumaila UR. Global fisheries losses at the exclusive economic zone level, 1950 to present. Marine Policy 2012; 36: 544-549.

7 Ruello NV. A study of the composition, value and utilisation of imported seafood in Australia. Canberra: Australian Government Fisheries Research and Development Corporation, 2011. http://www.apfa.com.au/wp-content/ uploads/2010/03/2010-222-DLD.pdf (accessed Mar 2012).

8 The Prime Minister's Science, Engineering and Innovation Council. Australia and food security in a changing world. Can we feed ourselves and help feed the world in the future? Report of the PMSEIC Expert Working Group. Canberra: PMSEIC, 2010. http://www.chiefscientist.gov.au/wp-content/uploads/ FoodSecurity_web.pdf (accessed Mar 2012).

9 Jungbluth N. Comparison of the environmental impact of tap water vs bottled mineral water. Uster, Switzerland: Swiss Gas and Water Association, 2006. http://aquadoc.typepad.com/waterwired/files/bottled_water_impact_lca.pdf (accessed Mar 2012).

10 Friel S, Dangour AD, Garnett T, et al. Public health benefits of strategies to reduce greenhouse-gas emissions: food and agriculture. Lancet 2009; 374 : 2016-2025.

11 Heat takes toll of Queensland wheat crop. ABC News 2009; 25 Aug. http:// www.abc.net.au/rural/news/content/200908/s2665966.htm (accessed Dec 2012).

12 CSIRO (Commonwealth Scientific and Industrial Research Organisation), Australian Government Bureau of Meteorology. State of the climate 2012. Canberra: CSIRO and BOM, 2012. http://www.bom.gov.au/announcements/ media_releases/ho/stateClimate2012.pdf (accessed Mar 2012).

13 Lea E, Worsley A. Australian consumers' food-related environmental beliefs and behaviours. Appetite 2008; 50: 207-214. 